\title{
Computers, communication and confidentiality: tales of Baron Munchausen
}

\author{
B Wright, D Bhugra, S J Booth
}

\begin{abstract}
The aim was to examine the use of computer and paper based systems in accident and emergency (A\&E) departments in the management of patients who are frequent attenders. More than half of the A\&E consultants in the Thames regions who were sent a questionnaire responded (44 of the 80 ). $82 \%$ of the respondents use such systems predominantly to monitor violent patients, those with Munchausen syndrome, and children on the "at risk" register. Systems currently in use fail to fulfil many of the functions that would be required of an ideal system. When using computers to store and communicate clinical data, several ethical problems were identified but these appeared to be outweighed by the practical need and were also present with paper based systems. Safeguards could also be built into computer based systems to reduce some of the ethical problems. Computer systems should be deliberately chosen and implemented in response to a specific management problem. The potential benefits should be weighed against possible damaging side effects, such as a breach of confidentiality. ( $\mathcal{F}$ Accid Emerg Med 1996;13:18-20)
\end{abstract}

Key terms: computer records; confidentiality; accident and emergency departments.

Among those patients who attend accident and emergency (A\&E) departments there is a heterogeneous subgroup whose needs are quite different from those who attend following trauma or first onset of an illness. This subgroup is characterised by frequent attendance at one or more medical units and a complex and difficult clinical or social history. Typical examples would include patients with sickle cell disease, haemophilia, or a child on the "at risk" register. The subgroup also contains intimidating and threatening patients, those who may become violent, and those with Munchausen syndrome. Management of the subgroup as a whole is often hampered by the relative inaccessibility of past information. The use of a "black list" is an informal, unaccountable, and unverified response to part of this problem.

Difficulty with communication represents a major problem, not only for the process of diagnosis but also for providing continuity of care. Using computers to store and communicate clinical information across units, districts, regions, and potentially across the nation could be a reality in this country ${ }^{1}$ and provide an effective solution. This wide net of communication could be considered as a treatment in its own right.

Our hypotheses were (1) that there are many systems (of which the "black list" is but one) currently in use, (2) that the existing systems fail to fulfil all the functions required of them, and (3) that there are ethical and pragmatic obstacles to the development and implementation of such a system, but that these were outweighed by the clinical need.

\section{Methods}

To examine these three hypotheses the study obtained data from a sample of $A \& E$ consultants in the four Thames regions. A questionnaire was used to ascertain firstly how and what information they currently held on patients who were difficult to manage, secondly what an ideal computer system should provide in this area, and thirdly some of the ethical implications that these systems present.

In December 1992 a single questionnaire was sent to all $80 \mathrm{~A} \& \mathrm{E}$ department consultants in the four Thames regional health authorities The questionnaire contained 17 closed questions. For 11 questions a positive response could be indicated and for six a Likert-type response was required. In addition, respondents were asked to comment on the name of systems in use in their department and to identify any ethical problems.

Of the 80 questionnaires posted, $47(59 \%)$ were returned, $44(55 \%)$ of which were usable. A postal survey was chosen because the data set required could be clearly defined and encoded, confidentiality of the respondents could be objectively assured, and the entire project could be carried out in a short time. (Copies of the questionnaire are available from the first author.)

\section{Results}

The results have been grouped under two headings: (1) the description of systems currently in use, together with the perceived attributes of an ideal system; (2) the ethical and practical issues related to the use of the hypothetical ideal system.

DESCRIPTION OF CURRENT SYSTEMS IN USE AND DESCRIPTION OF AN IDEAL SYSTEM Only $18 \%$ (8/44) of those responding did not keep records of those patients who are difficult to manage. The majority of the respondents $(82 \%, 36 / 44)$ did keep records; $57 \%$ (25/44) used a paper based system, $16 \%(7 / 44)$ used a computer based system, and $9 \%(4 / 44)$ used both.

S J Booth

Correspondence to: Dr B Wright. 
Table 1 Percentage of consultants currently keeping an additional record of patient subgroups and the number who would like to keep records in an ideal system.

\begin{tabular}{lcc}
\hline Condition to be recorded & $\begin{array}{l}\text { Consultants currently } \\
\text { holding additional } \\
\text { information on } \\
\text { patient group } \\
(n=44)\end{array}$ & $\begin{array}{l}\text { Ideal system } \\
(n=44)\end{array}$ \\
\hline Brittle diabetes & $8(19 \%)$ & $28(64 \%)$ \\
Brittle asthma & $12(28 \%)$ & $30(68 \%)$ \\
Severe epilepsy & $12(28 \%)$ & $30(68 \%)$ \\
Sickle cell disease & $5(12 \%)$ & $26(59 \%)$ \\
Haemophilia & $6(14 \%)$ & $32(73 \%)$ \\
HIV & $6(14 \%)$ & $24(55 \%)$ \\
COAD & $12 \%)$ & $11(25 \%)$ \\
Violent patients & $14(33 \%)$ & $33(75 \%)$ \\
Munchausen syndrome & $32(74 \%)$ & $39(89 \%)$ \\
Psychiatric patients & $4(9 \%)$ & $15(34 \%)$ \\
Children on the at risk register & $23(53 \%)$ & $39(89 \%)$ \\
Patients with no fixed abode & $3(7 \%)$ & $15(34 \%)$ \\
Socially vulnerable patients, for example young runaways & $7(16 \%)$ & $21(48 \%)$ \\
\hline
\end{tabular}

$\mathrm{HIV}=$ human immunodeficiency virus $\mathrm{COAD}=$ chronic obstructive airways disease

Table 2 Type of information currently kept on each patient and the type of information that would be kept in an ideal system.

\begin{tabular}{|c|c|c|}
\hline Type of information kept on each patient & $\begin{array}{l}\text { No currently holding } \\
\text { information } \dagger \\
(n=36)\end{array}$ & $\begin{array}{l}\text { Information for } \\
\text { ideal system } \\
(n=42) \dagger\end{array}$ \\
\hline $\begin{array}{l}\text { Identification of patient by name only } \\
\text { Identification of the patient using external criteria, } \\
\text { for example height, weight, skin colour, scars, } \\
\text { tattoos, and other distinguishing criteria }\end{array}$ & $13(36 \%)$ & $11(26 \%)$ \\
\hline $\begin{array}{l}\text { Description of diagnosis } \\
\text { Description of presenting symptoms } \\
\text { Description of presenting signs } \\
\text { Outcome of investigations } \\
\text { Description of the patient's normal behaviour }\end{array}$ & $\begin{array}{r}14(39 \%) \\
9(25 \%) \\
8(22 \%) \\
1(3 \%)\end{array}$ & $\begin{array}{l}40(98 \%) \\
34(83 \%) \\
28(68 \%) \\
22(54 \%)\end{array}$ \\
\hline $\begin{array}{l}\text { or clinical history } \\
\text { Account of current management plan }\end{array}$ & $\begin{array}{r}4(11 \%) \\
10(28 \%)\end{array}$ & $\begin{array}{l}27(66 \%) \\
35(85 \%)\end{array}$ \\
\hline
\end{tabular}

tThe denominator varies between groups because some respondents do not currently operate a system.

The questionnaire identified that the records were maintained informally on $37 \%(13 / 35)$ of the sites. On $37 \%$ of the sites (13/35) they were formally maintained by nursing staff, on $29 \%$ (10/35) they were maintained by medical staff, and on $11 \%(4 / 35)$ they were maintained by the receptionist. A record was kept of the personnel responsible for entering the data on $31 \%(8 / 26)$ of the sites, and on $69 \%$ of the sites $(18 / 26)$ no such record was kept. Where the hospital had received fax messages and circulars on difficult patients, only $7 \%(3 / 41)$ did not keep them.

Consultants were asked to identify firstly which types of patients are held on existing systems and secondly which patient groups should be held on an ideal system. These responses are shown in table 1.

Table 3 Response to the question asking the degree of benefit in holding information on a computer system for different groups of patients who attend frequently.

\begin{tabular}{lllll}
\hline Patient group & Essential & Beneficial & Irrelevant & Detrimental \\
\hline Medical problem $(\mathrm{n}=37) \dagger$ & $10(27 \%)$ & $24(65 \%)$ & $3(8 \%)$ & 0 \\
Psychiatric problem $(\mathrm{n}=34)$ & $8(24 \%)$ & $26(76 \%)$ & 0 & 0 \\
Munchausen syndrome $(\mathrm{n}=42)$ & $18(43 \%)$ & $22(52 \%)$ & $2(5 \%)$ & 0 \\
Social problem $(\mathrm{n}=40)$ & $13(32 \%)$ & $23(58 \%)$ & $4(10 \%)$ & 0 \\
\hline
\end{tabular}

$\mathrm{t}_{\mathrm{n}}=$ number of consultants responding.

Table 4 Number of respondents who would support dissemination of patient details to differing areas around the country.

\begin{tabular}{|c|c|c|c|c|c|}
\hline $\begin{array}{l}\text { Respondents supporting dissemination } \\
\text { of data by geography }\end{array}$ & $\begin{array}{l}\text { None } \\
\text { at all }\end{array}$ & District & Region & $\begin{array}{l}\text { Bordering } \\
\text { regions }\end{array}$ & Nation \\
\hline Number of responders $(n=42)$ & $\begin{array}{l}0 \\
(0 \%)\end{array}$ & $\begin{array}{l}6 \\
(14 \%)\end{array}$ & $\begin{array}{l}17 \\
(40 \%)\end{array}$ & $\begin{array}{l}3 \\
(7 \%)\end{array}$ & $\begin{array}{l}16 \\
(38 \%)\end{array}$ \\
\hline Cumulative total & 0 & $\begin{array}{l}42 \\
(100 \%)\end{array}$ & $\begin{array}{l}36 \\
(86 \%)\end{array}$ & $\begin{array}{l}19 \\
(45 \%)\end{array}$ & $\begin{array}{l}16 \\
(38 \%)\end{array}$ \\
\hline
\end{tabular}

When asked what type of system they would prefer, $7 \%$ (3/41) preferred a paper based system, 39\% (16/41) a single stand alone PC in the department, $49 \%(20 / 41)$ a system attached to the main hospital system, and 5\% (2/41) either a PC or a mainframe.

Responses showing the level of information held for each patient and the preferred level of information are shown in table 2 .

\section{RESPONDENTS' VIEWS ON ETHICAL AND}

PRACTICAL ISSUES

When asked if they perceived any ethical problems in the use of such a system, $2 \%$ (1/41) answered "many", 41\% (17/41) "few", and 56\% (23/41) "none". The ethical problems identified in the free text fell into three categories: providing and maintaining accurate information, restricting access to the information held to maintain confidentiality, and the possibility of an inappropriate response by staff to the patient as a result of the information made available.

Respondents were also asked to assess the effect that having additional information would have on patient management. These findings are shown in table 3.

Respondents were asked if they would "regard the widespread dissemination of confidential patient information to the different hospitals as a breach of patient confidentiality?" Twelve percent (5/41) of the respondents answered "very definitely" or "definitely"; 44\% (18/41) "possibly"; 34\% (14/41) "definitely not"; and 10\% (4/41) "very definitely not".

Given the ethical and practical difficulties related to providing other units with clinical information on difficult patients, clinicians were asked to what extent they would support dissemination of information to surrounding and more distant areas. The results are shown in table 4.

\section{Discussion}

The use of a postal questionnaire prevented assessment of non-respondents. The absence of a skew to any one region makes it likely that the results were representative; against this is the high percentage $(82 \%)$ of respondents who acknowledged keeping additional records, and it is possible that those with a greater interest answered. The questionnaire itself was limited by the closed design and this may not be appropriate when considering open ended ethical issues, even given the option of free text entry. On balance it would appear that the closed questionnaire design encouraged the high response rate.

It is evident that the majority $(82 \%)$ of departments currently use a system to record additional information on difficult patients. The main patient types were children on the "at risk" register (53\%) and Munchausen patients $(74 \%)$, both exemplifying situations where third party information is essential for patient management. One third of respondents kept information on violent patients and nearly all the hospitals supplemented their own data with circulars sent from other hospitals. These 
systems appear to be varied. A comparison between the types of patients and information currently recorded on a system and what would be required on an ideal system (tables 1 and 2) show that current systems are far from ideal and fail to fulfil the functions required of them.

\section{ETHICAL ISSUES}

Despite their widespread use it was evident that the systems were not free of ethical difficulties. A significant minority $(41 \%)$ felt that there were some ethical problems associated with these systems. The most consistent and frequent concern was maintaining confidentiality. The clinical information itself can cause harm once it has been linked to the given individual outside the clinical domain. ${ }^{2}$ With well developed systems there are practical ways in which access can be restricted. ${ }^{3}$ Further areas of concern are the quality of the information and the effect of this information on patient management. The information held on the patient represents a model of the real patient. ${ }^{4}$ The degree to which this model is accurate will depend on the complexity, quality, and quantity of the information held, which would in turn be determined by the system and the frequency with which the data were refreshed. What is not clear is optimum amount of information, as more is not always better. Further work is needed in this area, but it would seem sensible to start with the data set requested by clinicians given in table 2 above.

If the information system is regarded as a treatment in its own right this emphasises the need for adequate training, not only in the mechanics of extracting appropriate data from the computer, but, more importantly, in how to integrate this information appropriately into clinical decision making. For the majority of patients the ethical problems associated with the use of the system can be circumvented by the use of informed consent. The most significant exception to this is the patient with Munchausen's syndrome.

The successful management of a patient with Munchausen's syndrome ${ }^{5}$ appears to have three phases in common..$^{6-10}$ The first is to collect sufficient information to make a diagnosis. The second is to contain the patient emotionally and, if necessary, physically, so that a supportive, planned, and non-punitive confrontation can be achieved. The third stage is to continue containment and long term support.

Work in other fields ${ }^{11}$ has shown that the expediency offered by a computer system over a paper based system is not the ethical issue. The key ethical issue is whether confidential information can be communicated between different clinical units without the patient's consent. From our survey it is evident that confidential information on patients is already disseminated widely, as $74 \%$ of the responders keep a record of patients with Munchausen's syndrome, and $93 \%$ keep records sent to them on difficult patients by other units. Furthermore, $95 \%$ of respondents believe that a computer tracking system is either essential or beneficial in managing patients with Munchausen's syndrome. Some system that communicates information on these patients would appear appropriate, as the alternative is to leave what is regarded as a psychiatric illness ${ }^{12}$ untreated, with the attendant morbidity, mortality, cost to society, and occasionally damage to other individuals. ${ }^{13}$

Attending health care workers have a responsibility not to use the information they obtain from the system in a punitive manner which is likely to perpetuate the cycle of self discharge and readmission. This can be achieved by training and by having a clearly stated management policy for the unit. ${ }^{14}$

\section{Conclusion}

Patients who attend A\&E departments frequently can present a challenging management problem. There is widespread use of systems that provide additional clinical information on these patients, thus improving communication between different doctors. This is a response to the difficulties in managing these patients and a course of action that appears to have widespread support. Now that it is cheap and easy to access any computer remotely through a modem it may be appropriate and costeffective to develop a universal system that would function in a more structured manner, with safeguards to protect both patients and clinicians. There are technical ways in which the ethical difficulties associated with such a system could be reduced.

1 Moon JP, Georgoulakis JM, Austin VR, et al. Developmen of the US Army ambulatory care data base. Milit Med 1990;155:181-5.

2 Lincoln TL. Privacy: a real-world problem with fuzzy boundaries. Methods Inform Med 1993;32:104-7.

3 Miller RA, Schaffner KF, Meisel A. Ethical and legal issue related to the use of computer programs in clinical medicine. Ann Intern Med 1985;102:529-36.

4 Kluge EHW. Advanced patient records: some ethical and legal considerations touching medical information space. Methods Inform Med 1993;32:95-103.

5 Asher R Munchausen's syndrome Lancet 1951;i:339-41.

6 Tucker LE, Hayes JR, Viteri AL, Liebermann TR. Factitial bleeding: successful management with psychotherapy Dig Dis Sci 1979;24:570-2.

7 Marriage K, Govorchin M, George P. Dilworth C. Use of an Amytal interview in the management of factitious dea mutism. Aust NZ F Psychiatry 1988;22:454-6.

8 Schlesinger RD, Daniel DG, Rabin P, Jack R. Factitiou disorder with physical manifestations: pitfalls of diagnosis and management. South Med $\mathcal{F}$ 1989;82:210-4.

9 Higgins PM. Temporary Munchausen syndrome. $\mathrm{Br} f$ Psychiatry 1990;157:613-6.

10 Cremona-Barbaro A. The Munchausen syndrome and its symbolic significance: an in-depth case analysis. $\mathrm{Br} \mathscr{F}$ Psychiatry 1987;151:76-9.

11 James AE, Erickson JJ, Carroll FE, et al. Medical image management: practical, legal and ethical considerations. management: practical, legal and
Comput Biol Med 1986;16:247-57.

12 World Health Organisation. The ICD-10 classification of mental and behavioural disorders; clinical descriptions and mental and behavioural disorders; clinical descriptions
diagnostic guidelines. (F68.1.) Geneva: WHO, 1992.

13 Sinanan K. Evolution of variants of the Munchausen syndrome. Br F Psychiatry 1986;148:465-7.

14 Bhugra D. Psychiatric Munchausen's syndrome: literature review with case reports. Acta Psychiatr Scand 1988;77: 497-503. 